\title{
The Connection of Solar Generators to the Electricity Distribution Network as a Means of Mitigating Environmental Impacts by Dispensing the Banks of Accumulators
}

\author{
Márcio Belloni, Thadeu das Neves Conti \\ IPEN/USP, São Paulo, Brazil \\ Email: prof.belloni@gmail.com, tnconti@yahoo.com.br
}

How to cite this paper: Belloni, M. and das Neves Conti, T. (2019) The Connection of Solar Generators to the Electricity Distribution Network as a Means of Mitigating Environmental Impacts by Dispensing the Banks of Accumulators. Energy and Power Engineering, 11, 392-397.

https://doi.org/10.4236/epe.2019.1112026

Received: September 24, 2019

Accepted: December 16, 2019

Published: December 19, 2019

Copyright $\odot 2019$ by author(s) and Scientific Research Publishing Inc. This work is licensed under the Creative Commons Attribution International License (CC BY 4.0).

http://creativecommons.org/licenses/by/4.0/

\begin{abstract}
Solar generators are known worldwide as a means of generating clean electricity. However, the existence of battery banks causes alarm in the community by the existence of materials that degrade the environment by discarding them outside the norm. With the publication of Regulatory Standards 482/12 and $687 / 15$, solar generators can be connected to the distribution grid, which serves as a means of accumulating the generated energy. The new changes were seen as an economic possibility, but there are more benefits. This has proved very important to make solar generation greener because it no longer needs large battery banks. This has also been shown to significantly lower the final value of the solar generator, bringing economic benefits. This paper aims to analyze the economic and environmental benefits of battery bank distribution in solar generation.
\end{abstract}

\section{Keywords}

Solar Energy, Decentralized Generation, Battery Banks, Renewable Energy

\section{Introduction}

Advances in the generation of electric energy by renewable means are currently a reality, making commercial means available to generate electricity by means of renewable energy, by means of solar, wind or hydroelectric dams.

However, of all the generators presented, the solar generator is the most viable in terms of renewable and ecological energy, with the advantage that it does not require maintenance with mechanical parts, as it happens with the wind power 
and the hydroelectric one of water, is silent, unlike the turbines of the others, and does not suffer as much with the climatic alterations as in the case of the periods of few winds and drought that affect the other generators.

By definition, solar energy consists of the energy contained in the electromagnetic radiation emitted by the Sun, product of the high temperatures of its surface (near $6000^{\circ} \mathrm{C}$ or, more exactly, $5.760 \mathrm{~K}$ ) [1].

But, an item of solar generators makes them harmful to the environment: the banks of accumulators. To ensure uninterrupted power supply, it is necessary for the solar generator to be fitted with a battery bank. With the advent of NR482/12 and NR687/15, there is the option of connecting the solar generators to the electricity distribution network, dispensing the use of the accumulator banks, or in case of an emergency system, limiting it only to the period of possible disconnection of the distribution system.

\section{Current Situation of Distributed Generation}

With the scarcity of fossil fuels, the pollution generated by fossil fuel plants, as well as climate change caused by the indiscriminate burning of fossil fuels, humanity is looking for a way out of clean electricity and renewable energy sources. According to the chart released by ANEEL, coal has been the most widely used source for electricity generation worldwide. It is inconceivable that in 2006 coal was used for $41 \%$ of electricity generation, compared with $59 \%$ for all other means.

Although there has been an appeal in recent years for the use of renewable energy, oil and coal have been the most widely used sources of electricity generation. Currently, coal is primarily responsible for power generation in several countries, such as the US and China, which produce most of the electricity used in the world. It is almost half of world production. According to ANEEL, "in Brazil, ore represents just over $1.5 \%$ of the electricity matrix. In 2007 , when 435.68 TWh were produced in the country, coal was responsible for generating 7.9 TWh, from the operation of thermal power plants located in the southern region, near the mining areas" [2].

It is verified that the distributed generation has many advantages over the centralized one, being a great diversifying agent and complementary of the energy matrix. It is known that by the law of thermodynamics, much of the electricity generated, is lost in the form of heat and magnetism in transmission and distribution. The very resistance presented by the transmission cables already justifies the advantage of the distributed generation. Another obstacle is that a centralized plant needs to be large, a large investment, and the destruction, often of local flora and fauna, as the case of impoundment for hydroelectric plants. People lose their dwelling, and what was a natural treasure is completely submerged under the waters of the dams.

We are experiencing difficulties regarding the supply of electric energy, including in the southeast of the country, where a drought puts the supply of electricity at large centers at risk. 
All conventional power plants have inherent problems such as pollution (oil or coal-fired power plants), dependence on fuel supply (oil, coal, uranium) or public opposition to their construction and operation (nuclear power plants, coal thermal and also hydroelectric). In addition, centralized power plants leave large numbers of consumers vulnerable to electrical blackouts. Distributed photovoltaic solar energy eliminates many of these problems. Photovoltaic systems integrated to urban buildings and interconnected to the public electricity grid, are the latest trend in this area and are justified because both the solar energy resource and the energy demand in urban buildings are distributed [3].

However, battery banks cause severe damage to nature and should be disposed of properly.

\section{Risks to the Environment}

Although solar generators have the status of renewable energy, in photovoltaic generators not connected to the grid, they are used as accumulators, lithium, stationary and lead-acid batteries, which are considered by the environmental standard as toxic waste when discarded. According to Conama, in Resolution $401 / 08$, in article sixteenth, the body of the product lead acid, nickel cadmium and mercury oxide must contain the warning about the risks to human health and the environment; and the need, after use, to be returned to retailers or the authorized service network to be transferred to manufacturers or importers [4].

Batteries should be disposed of in specialized stores, where the cadmium, lead, mercury and other materials can contaminate a large area, extending to plants and animals [5].

Thus, its disposal is considered special and can not be left to solid waste collection agents, but under the responsibility of the consumer, who must, in reverse logistics, provide the correct disposal, according to Law 12.305/2010. Article thirty-three, with the return of products after use by the consumer, regardless of public urban cleaning and solid waste management services, manufacturers, importers, distributors and traders of batteries and accumulators are required to structure and implement logistics systems reverse [6].

Decreasing the use of accumulators generates benefits to nature, costs less the consumer who no longer needs to worry about the reverse logistics path in the disposal of them.

The lack of regulation to which the consumer must obligatorily return the accumulator of energy to the manufacturer makes difficult for the correct treatment of the same. Clearly, taking this obligation to the consumer would be impracticable, since enforcement is practically impossible in this sense.

The cost to adopt measures that contemplate the environmental issue is added to the finances of the companies, expenses that few organizations want to have. In Brazil there are only standards for a computer component that contains heavy metals: the battery, with nickel and cadmium. According to resolution 257, the National Environmental Council (CONAMA), industries are required to receive 
used batteries, forwards controlled landfill or recycling, except that the consumer is not obliged to deliver them. The sign of return is very low (SPCTi Recycling, 2009, para. 6).

Although the amount is small of accumulator returns, few companies incubate to give correct allocation to them. Thus, a large number of accumulators are the responsibility of a few companies located only in large urban centers. The Info Exame Magazine (2009) brings some organizations that have been working with recycling technology products.

Suzanquim, located in Suzano-SP, receives 700 tons of batteries every month. The plastic that can be harnessed is separated, the leftover material goes through a chemical process and then is burned in an oven at 1300 degrees Celsius. The incinerated batteries in the recycling industry result in oxides of metal salts used to make dyes for the manufacture of paints [7].

\section{Unviability of the Battery Banks}

Accumulators of good quality and durability are expensive and significantly increase the final cost of the project. For example, one can observe the Bosch stationary battery, model P5 $401220 \mathrm{Ah} / 240 \mathrm{Ah}$. Initially, the technical specifications of the battery indicate $12 \mathrm{v}$ voltage and $220 \mathrm{Ah}(20 \mathrm{hr})$ at $240 \mathrm{Ah}(100 \mathrm{hr})$; dimensions of $530 \times 280 \times 246(\mathrm{~mm})$ and weight of $60 \mathrm{Kg}^{1}$. In a simplified calculation to arrive at an Ah value, we can use a variation of the notion of power calculation:

$$
B_{C}=\frac{T_{C} \cdot A u t}{B_{V} \cdot D}
$$

- $B_{c}=$ Battery capacity (Ah-Ampere-hour);

- $T_{c}=$ Total Consumption (Wh/day-Watt-hour/day);

- $A u t=$ Autonomy (days);

- $B_{v}=$ Battery Voltage $(\mathrm{V})$;

- $D=$ Discharge depth.

It is worth remembering that the autonomy in homes is usually 2 or 3 days, and to maintain a longer useful life, the battery charge depth should be at least 0.5 . For a residence that consumes $250 \mathrm{kWh} /$ month, we will have $8.34 \mathrm{kWh} /$ day.

$$
B_{C}=\frac{8334 \times 3}{12 \times 0.5} B_{C}=4166.67 \mathrm{Ah}
$$

Thus, the hypothetical accumulator bank must support $4166.67 \mathrm{Ah}$, that is, it should consist of 18 batteries of $240 \mathrm{~A}$ each. That is, using a Bosch accumulator bank model P5 $401220 \mathrm{Ah} / 240 \mathrm{Ah}$ [8], will require 18 batteries, totaling an expense of R\$17856.00 (Seventeen thousand, Eight Hundred and Fifty Six Brasilian Reals) in accumulators, which with this discharge depth factor, should have a durability of 5 years [9].

With the advent of NR 482/12 [10] and NR 687/15 [11], the particular solar generator, instead of being connected to battery banks, is connected directly to 
the electricity distribution. The photovoltaic system connected to the grid does not use batteries for energy storage, since the grid itself is used as a storage medium. All the energy generated by the photovoltaic system is immediately injected into the grid, being consumed internally or exported to the concessionaire, according to the instant generation and consumption levels. In practice, a residence or company that has a photovoltaic system within the credit compensation system starts to consume less or no electricity from the public grid, and can zero its electricity bill at the end of the month.

The economy with the battery bank and charge controller, in addition to the environmental appeal, alone justifies the use of the solar generator connected to the grid.

\section{The Advances of NR482/12 and NR687/15}

Recently, two standards have made it possible to connect generators with renewable energies in utility distribution networks.

It is a system where the excess generated energy is sent and stored in the utility's distribution system. Such energy is returned to the system user when the generators are low producing uninterrupted power supply to the user's network.

This system sets up an electric energy storage service, a loan where the difference between power sent to the distribution system and the system received is computed, and the user must pay what he used excessively or obtain a credit that can be used by it on the same connected unit or other installation of its own.

\section{Conclusions}

Regulatory Standards 482/12 and 687/15 not only delivered a distributed power solution to the user, but also brought solar generators closer to clean energy ideals, eliminating the need for polluting and extremely expensive battery banks.

With the connection to the distribution network, we should also facilitate the purchase of solar generators, which become more affordable. In Table 1 and Table 2, the average price of the grid mode solar generator is $\$ 17660.00$ and

Table 1. Average price of generator on grid [12].

\begin{tabular}{cc}
\hline Company & System Cost Brazilian Real (R\$) \\
\hline A & 13.40000 \\
B & 19.99000 \\
C & 19.59000 \\
Average & 17.66000 \\
\hline
\end{tabular}

Table 2. Average price of generator off grid [12].

\begin{tabular}{cc}
\hline Company & System Cost Brazilian Real (R\$) \\
\hline A & 29.90500 \\
B & 26.26100 \\
Average & 28.08300 \\
\hline
\end{tabular}


off-grid for the same power is $\$ 28083.00$. As such, it eliminates battery banks that account for almost $40 \%$ of their total price.

\section{Conflicts of Interest}

The authors declare no conflicts of interest regarding the publication of this paper.

\section{References}

[1] Silva, E.P. (2014) Renewable Energy Sources: Energy Production for Sustainable Development. Livraria da Física, São Paulo.

[2] Aneel, Agência Nacional de Energia Elétrica (2008) Atlas of Electricity from Brazil. 3rd Edition, Brasília.

[3] Rüther, R. (2004) Photovoltaic Solar Buildings: The Potential of Solar Photovoltaic Generation Integrated to Urban Buildings and Interconnected to the Public Electricity Grid in Brazil. UFSC/LABSOLAR, Florianópolis.

[4] Conama (2008) Resolution No. 401, de 11/04/2008. 108-109.

[5] Luiz, A.M. (2013) Solar Energy and Preservation of the Environment. Livraria da Física, São Paulo.

[6] Republic of Brazil Law 12.305/2010. Establishes the National Solid Waste Policy. https://www.gov.br/planalto/pt-br

[7] Vieira, K.N., Olívia Rodrigues, T. and Rodrigues, L. (2009) The Reverse Logistics of Technological Waste: A Study on Braskem's Collection of Bulbs, Batteries and Batteries. Revista de Gestão Social e Ambiental, 3.

[8] Belloni, M. (2017) Distributed Photovoltaic Generation: Technical and Legal Aspects. Novas Edições Acadêmicas, BeauBassim.

[9] Reis Baterias. E-Commerce (On Line). https://www.bateriaautomotiva.com.br

[10] Agência Nacional de Energia Elétrica, ANEEL (2012) Normative Resolution No. 482.

[11] Agência Nacional de Energia Elétrica, ANEEL (2015) Normative Resolution No. 687.

[12] Bozo, A.C.M.R., Cremasco Gabriel, C.P. and Gabriel Filho, L.R.A. (2015) Cost Analysis of on-Grid and off-Grid Photovoltaic systems in Brazil. ANAP Brazil Scientific Magazine, 8, 57-66. https://doi.org/10.17271/1984324081220151138 